\section{Effects of stimulus incongruity on children's curiosity as measured by looking time and expression change*}

\author{
MARGARET R. CONNOLLY and LAUREN HARRIS \\ Michigan State University, East Lansing, Mich. 48823
}

Sixty children, ranging in age from $j$ to 11 years, looked at a series of congruous (i.e., normal) pictures (animals and other objects) and at pictures of incongruous objects formed by mismatched combinations of heads and bodies of the congruous objects. Afterwards, the children were asked to give names to all the pictures. The results disclosed longer looking times, more sustained expression changes, and greater likelihood of expression change to the incongruous than to the congruous pictures. Further, older children were more likely than younger children to recognize and respond to incongruity according to these measures and also were more likely to name both components of the incongruous pictures.

Berlyne (1960) has proposed a number of stimulus characteristics, or "collative properties," that induce perceptual exploration. These include novelty, complexity, uncertainty change, surprisingness, conflict, and incongruity. The latter-incongruitythe property with which the current study is concerned-is defined by Berlyne as the arousal of an expectation that is disappointed by simultaneously perceived elements or by elements perceived in close succession. Incongruous stimuli provide conflicting, therefore insufficient, information for immediate perceptual resolution. Consequently, according to Berlyne, a state of high arousal results which may be assuaged by visual exploration.

Of all the collative variables, incongruity is among the least studied, and only a very few studies with children have been reported. Of these, the results have been inconsistent. Clapp \& Eichorn (1965) and Lore (1965) found greater responsiveness to incongruous than to congruous stimuli for preschool and kindergarten children, while Burgess (1957) did not.

Like the studies of novelty and complexity, the measure of responsiveness in these studies was the duration of time spent looking at the

*This paper is based on a thesis submitted by the first author, under the second author's direction, in partial fulfillment of the MA degree requirements. We are grateful to Beverly Hunt, Principal, and the staff and children of the Spartan Village Public School, East Lansing, Mich., for their cooperation. Thanks also are due Bernand White for serving as one of the $O$ and Merrill M. Mitler for help with data analysis. Requests for reprints should be sent to Lauren Harris, Department of Psychology, Michigan State University, East Lansing, Mich. 48823 . stimulus or the number of discrete looks. Commonsensically, incongruity should induce a change of expression as well as a lengthened time of visual inspection. Incongruous stimuli ought to perplex or puzzle if the $O$ has a schema or standard for congruity with which to compare the incongruous stimulus. Indeed any kind of differential response to incongruity presupposes the existence of such a standard. The puzzlement, one would think, ought to show in the O's face. Yet with only a few exceptions [e.g. Kagan, Henker, Hen-Tov, Levin, \& Lewis's (1966) use of facial expression change as an index of infants responses to novelty], such affective responses have not been studied in research on collative properties. In research with children, who, unlike adults in experimental situations, are quite openly expressive (see Miller, 1960), change of facial expression ought to be a good measure of detection of incongruity.

The present study, therefore, used both looking time and expression change as measures of children's responsivity to incongruity. An incongruous stimulus was operationally defined as a picture whose component parts the child had seen previously but always in a different juxtaposition.

Our expectation was that the mean duration of looking time and the incidence of expression change would be greater to incongruous pictures than to congruous pictures. We also expected the reaction to incongruity to be stronger among the older than among the younger children inasmuch as the recognition of incongruity may be presumed to increase with increased experience.

\section{SUBJECTS}

The Ss were 20 kindergarteners (5 years, 3 months to 6 years, 10 months), 20 second-graders $(6: 2 \cdot 8: 5)$, and 20 fourth-graders $(9: 2-11: 7)$. There were 9 boys and 11 girls per grade.

\section{MATERIALS}

Fifteen congruous pictures and 15 incongruous pictures were prepared The congruous pictures were ditto copies of line drawings of a car, an airplane, and familiar animals. The incongruous pictures were made of combinations of parts of the congruous set such that in each case the completed incongruous picture had the head of one figure and the body of another.

Four different orders of presentation of the 15 congruous and 15 incongruous pictures were prepared as follows: each block of 10 pictures contained 5 congruous and 5 incongruous pictures; there were no more than 3 congruous or 3 incongruous pictures in succession; 1 congruous and 1 incongruous picture constituted the first pictures in each set of 30. Each set of pictures was bound into an $11 \times 18$ in. folder. The first page was blank.

This "picture book" was placed on a bookrest to permit easy view of the pictures for all children. A pilot study indicated that most kindergarten children could identify all the congruous animals and could handle the books in which the pictures were bound with skill sufficient to that needed in the task.

Children were tested individually in a spare room in the school. The door of the room contained a one-way mirror, in front of which was the table for the bookrest. The child sat facing the bookrest and $7 \mathrm{ft}$ from the mirror. The $\mathrm{E}$ demonstrated how to turn one page at a time, then told the child to do the same and to look at each picture for as long as he wished. The $\mathrm{E}$ then moved to a chair in the corner of the room approximately $6 \mathrm{ft}$ from the child, from which position she could see his eyes clearly but could not see the picture at which he was looking. As she moved to this position, she told the child that she had some "work to do" and she began to look at some papers. If the child looked up and sought her eyes, or if he smiled or laughed and tried to elicit some response from her (e.g., by exclaiming, "Boy, isn't this a funny one!"), she looked at him briefly, smiled slightly, and then looked down again to her "work." The intent was that she appear disinterested in the child's reactions to the pictures but not punitively inattentive to the child himself. This tactic seemed to have worked insofar as could be judged from the children's general behavior during the session.

After the child had looked at the 
Table 1

Mean Duration Looking Times to Incongruous and to Congruous Figures as a Function of Grade in School and Trial Block

Grade in School

\begin{tabular}{|c|c|c|c|c|c|c|c|c|}
\hline & \multicolumn{2}{|c|}{ Kindergarten } & \multicolumn{4}{|c|}{ Grade in School } & \multicolumn{2}{|c|}{ Total } \\
\hline & $\begin{array}{l}\text { Incon- } \\
\text { gruous }\end{array}$ & $\begin{array}{l}\text { Con- } \\
\text { gruous }\end{array}$ & $\begin{array}{l}\text { Incon- } \\
\text { gruous }\end{array}$ & $\begin{array}{l}\text { Con- } \\
\text { gruous }\end{array}$ & $\begin{array}{l}\text { Incon- } \\
\text { gruous }\end{array}$ & $\begin{array}{l}\text { Con- } \\
\text { gruous }\end{array}$ & $\begin{array}{l}\text { Incon- } \\
\text { gruous }\end{array}$ & $\begin{array}{l}\text { Con- } \\
\text { gruous }\end{array}$ \\
\hline \multicolumn{9}{|c|}{ Trial Block I } \\
\hline Mean & 10.3 & 8.5 & 10.4 & 8.7 & 8.6 & 7.0 & 9.7 & 8.1 \\
\hline SD & 7.2 & 4.8 & 3.9 & 4.1 & 1.9 & 1.2 & 4.3 & 3.4 \\
\hline \multicolumn{9}{|c|}{ Trial Block II } \\
\hline Mean & 6.7 & 6.3 & 8.6 & 7.2 & 7.7 & 5.7 & 7.7 & 6.4 \\
\hline SD & 3.3 & 2.6 & 2.8 & 2.3 & 2.0 & 1.0 & 2.7 & 2.0 \\
\hline \multicolumn{9}{|c|}{ Trial Block III } \\
\hline Mean & 5.3 & 4.8 & 6.7 & 5.9 & 6.3 & 5.4 & 6.1 & 5.4 \\
\hline SD & 2.2 & 2.2 & 1.9 & 1.6 & 1.2 & 1.1 & 1.8 & 1.6 \\
\hline \multicolumn{9}{|l|}{ Total } \\
\hline Mean & 7.4 & 6.5 & 8.6 & 7.3 & 7.5 & 6.0 & 8.0 & 7.7 \\
\hline $\mathrm{SD}$ & 4.2 & 3.2 & 2.9 & 2.6 & 1.7 & 1.1 & 2.0 & 2.3 \\
\hline
\end{tabular}

last picture, the E said, "Now I'd like you to look at each picture again and name it for me." If the child paused or asked for the name, the E said, "You give it a name; tell me what it looks like." The $E$ was careful to not suggest that more than one name might be correct or, indeed, that there was a correct name at all.

\section{APPARATUS}

The recording apparatus was a four-channel Rustrak event recorder, located outside the room and operated simultaneously by the $E$ and by two Os. The E's hand control was concealed and operated silently. The Os were seated in the adjoining room $11 / 2 \mathrm{ft}$ behind the one-way mirror. A screen concealed the $O$ s so that the child could not see them as he entered the room.

The $E$ recorded onset and duration of looks at a picture by pressing the button on her hand control as soon as the child began to look at each picture and by releasing the button whenever the child looked away from the picture. The first $O$ recorded each page turn with two "blips" of a second control and, with the third control, recorded onset and duration of the child's changes of expression. The second $\mathrm{O}$, using a fourth hand control, recorded onset, duration, and offset of the child's looks at the $E$.

\section{DEPENDENT VARIABLES}

Duration of looking time was defined as the length of time the child looked at the picture. It was calculated as the difference between the total picture exposure time and the duration of looks away from the picture (such as might occur when the child looked up at the E).

An expression change was defined as any change in expression while the child looked at each picture. Expressions such as the following were recorded: smiles, frowns, laughs, raised eyebrows, opened mouth, creased forehead. The sum of the duration of the expressions was used.

\section{RELIABILITY OF}

\section{DEPENDENT VARIABLES}

The reliability for each dependent variable was assessed in a pilot study according to the formula: total $\mathrm{n} \mathrm{um} \mathrm{b} \mathrm{r}$ of overlapping recordings/total number of separate recordings $\mathbf{x} 100 \%$. The agreement between the two Os for looks at the $\mathrm{E}$ was $83.1 \%$; for expression change, $76.5 \%$. The agreement between the $\mathrm{E}$ and $O s$ for nonorientation to the stimulus was $96.8 \%$. The agreement for looks at the E undoubtedly would have been higher, but only those looks on which there was complete overlap were counted.

\section{RESULTS AND DISCUSSION}

Duration of Looking Time

An analysis of variance of the looking time scores, with incongruity-congruity and trial block as "within-S" variables and school grade as the "between-S" variable, disclosed significant effects for the congruity-incongruity dimension $(F=19.5, \mathrm{df}=1 / 114, \mathrm{p}<.01)$ and trial blocks $(F=17.8, \quad \mathrm{df}=2 / 114$, $\mathrm{p}<.01)$. No other main effects and no interactions were significant.

Table 1 lists the means and standard congruous and incongruous pictures for each grade across trial blocks. The congruity-incongruity difference was in the predicted direction: children at each grade level in each trial block looked longer at the incongruous pictures than at the congruous pictures, though the difference was in fact small $(\bar{X}=8.0 \mathrm{sec}$ for incongruous, $7.7 \mathrm{sec}$ for congruous). The trial block effect, in the absence of a Trial Block by Grade interaction $(F<1.0$ ), reflects a regular decrease across trials in duration of looking times with both kinds of pictures. Probably the decrease reflects the accumulated familiarity of the pictures over trials or perhaps an increasing deviations for looking times to fatigue or boredom with the task.

Though the predicted grade effect was not significant $(F<1.0)$, inspection of the differences between mean duration of looking times with the two kinds of pictures suggests the predicted increase in responsiveness from congruity to incongruity, from kindergarten to fourth grade. The differences were $.91 \mathrm{sec}$ for $\mathrm{k}$ indergarteners, $1.30 \mathrm{sec}$ for second-graders, and $1.47 \mathrm{sec}$ for fourth-graders.

Another way to examine grade differences would be to consider scores of individual children. In how many individual cases did children look longer, on the average, at the incongruous pictures than at the congruous pictures? Across the three trial blocks, these numbers, for the kindergartners, were 14,12 , and 9 ; for the second-graders, 14,14 , and 11 ; and for the fourth-graders, 14,15 , and 16. Thus in the first trial block, there were no grade differences, but in Trial Blocks 2 and 3 , the number of kindergartners and second-graders looking longer at the incongruous pictures remained constant or decreased, while the number of fourth-graders increased. Though the changes are small, they are in a direction consistent with the prediction of grade differences.

Duration of Expression Change

The children showed a wide range of expressions to the pictures. For example, one girl pursed her lips, held her mouth wide open and her chin slack; a boy frowned, screwed up his whole face, and raised his eyebrows, usually accompanying this expression change by naming the picture in the form of a question (e.g., "Is this a horse?!). Strong intense expression changes typically occurred to incongruous pictures. Weak expression changes, such as weak smiles (turning up slightly the corners of the lips), also occurred to incongruous pictures, but typically, only weak expression changes occurred to congruous pictures when expression changes were made at all.

Across all $S$ s the mean duration of expression change was $2.35 \mathrm{sec}$ to incongruous pictures $(\mathrm{SD}=0.85)$ and was $0.70 \mathrm{sec}$ to congruous figures $(\mathrm{SD}=0.59)$. Analysis of variance indicated that this difference was significant $(F=19.87, \quad \mathrm{df}=1 / 240$, $\mathrm{p}<.0005)$. The analysis also disclosed a significant book effect $(F=2.81$, $\mathrm{df}=3 / 48, \mathrm{p}<.05$ ). No other main effects or interactions were significant. We have no explanation for the "book effect." It is worth noting, however, that duration of expression change was greater to incongruous than to congruous figures for all four books; the difference was simply significantly 
greater for one book than for the remaining three.

We had wondered whether, contrary to our general predictions of age differences, the kindergarten and second-grade children might show somewhat longer expression changes on the possibility that they would be somewhat less guarded than the fourth-grade children. Comparison of the scores across grades, however, failed to disclose any significant differences. If anything, there was a suggestion of greater duration of expression change among the older children.

In a recent study by Zigler (cited by Kagan, 1967), laughing and smiling to cartoons were found to increase through Grade 4 and then to decline. Kagan suggests that it is the "moderate amount of mismatch between event and schema" that is pleasurable. This seems a plausible explanation for the affective reactions to incongruity as well and suggests the need for extending the current study beyond the fourth grade. It is possible that the same curvilinear relation between expression change and age will obtain for incongruous pictures as for cartoons.

Frequency of Expression Change

The total numbers of expression changes to the 15 congruous pictures and to the 15 incongruous pictures were tabulated, but a one-way analysis of variance indicated that these scores were not different $(\mathrm{F}<1.0)$. It occurred to us that the absence of significant differences on this measure might have resulted, at least in part from the fact that the duration of expression change was longer to incongruous pictures than to congruous pictures and that, as we have noted above, the longer expression changes typically were more intense. Thus, several weak expression changes could be made in the time required for one intense expression change, so that the frequency-of-expression-change effect might have been attenuated.

For these reasons, a new statistic, occurrence of the first expression change, was employed. Only the first expression change to a picture was counted; all others were disregarded. The computation yielded 270 reactions on a total of 900 trials $(30 \%)$ on which incongruous pictures appeared and 85 reactions on 900 trials $(9 \%)$ on which congruous pictures appeared. For purposes of analysis, the proportion of the 15 incongruous pictures to which each child had made an expression change was subtracted from the proportion of the 15 congruous pictures to which he had made an expression change. A direct-difference $t$ test of the mean of the differences for all Ss indicated that the proportion of expression changes to the incongruous pictures was significantly greater $(\mathrm{p}<.0001)$.

There were 17 Ss for whom the incidence of first expression change for all 15 incongruous pictures was greater than or equal to $50 \%$ and less than 50\% for all congruous pictures. More than $75 \%$ of the Ss at each grade level responded more to the incongruous than to congruous pictures. Furthermore, there appeared to be a slight but direct relation between grade in school and total number of expression changes to incongruous pictures. Again, this difference is in a direction consistent with the predicted age differences.

\section{Picture Naming}

No child failed to give the correct name, or at least the correct class name, to the animals or objects in the congruous pictures. For example, a picture of a flamingo frequently was called a "bird," a "stork," or an "ostrich."

For the incongruous pictures, a child was presumed to have perceived both components if he labeled both correctly or if he mislabeled one (i.e., if his name for one component was, in fact, incorrect but nevertheless was different from his name for the other component, e.g., if the child said, "It's a duck with a dog's head," for the picture of the duck with the wolf's head). The results indicated that the majority of the children either consistently acknowledged only one component in each incongruous picture or consistently acknowledged both components. Across all Ss, $76 \%$ of the incongruous pictures (681 of 900) were "named" correctly. The results also indicated a direct relation between age of $S$ and tendency to acknowledge both components in the incongruous pictures. The mean number of components per incongruous picture named by the kindergartners was 1.56 , by the second-graders, 1.72 , and by the fourth-graders, 1.93. Thus the fourth-graders tended to acknowledge incongruity in nearly every picture. Probably because of the narrowness of the range of scores, an analysis of variance indicated that these differences were only marginally significant (grade effect: $F=2.88$, $\mathrm{df}=2 / 57, \quad \mathrm{p}>.05<.10)$. Even so, they, like the scores for looking time and number of first expression changes, are in a direction consistent with the predicted age differences. They also suggest that picture naming might be a most useful measure of sensitivity to incongruity. The child who names both components of the incongruous picture indicates that he detects at one time two elements that do not usually occur together. By this measure, the older the child, the more likely he was to detect incongruity in the pictures presented in the task.

In conclusion, the results indicate that duration of looking time, expression change (as measured both by duration of change and incidence of first expression changes), and picture naming are all valid indexes of recognition of stimulus incongruity and that, generally, recognition of and responsiveness to incongruity increases with chronological age, at least within the age range included here.

\section{REFERENCES}

BERLYNE, D. E. Conflict, arousal, and curiosity. New York: McGraw-Hill, 1960 BURGESS. S. E. (Cited in Berlyne. D. E.) Conflict and information-theory variables as determinants of human perceptual curiosity. Journal of Experimental Psychology, 1957,53, 388-404.

CLAPP. W. F. \& EICHORN, D. H. Some determinants of perceptual investigatory responses in children. Journal of Experimental Child Psychology, 1965, 2, $371-388$.

KAGAN, J., HENKER, B., HEN-TOV, A. LEVIN, J., \& LEWIS, M. Infants differential reactions to familiar and distorted faces. Child Development. $1966,37,519-532$.

KAGAN, J. On the need for relativisim. American Psychologist, 1967, 22, 136.

LORE, $R$. K. Some factors influencing the child's exploration of visual stimuli. Unpublished doctoral dissertation. University of Tennessee. 1965

MILLER. D. R. Motivation and affect. In $P$. Mussen (Ed.), Handbook of research methods in child development. New Yonk: Wiley, 1960. 